Check for updates

Cite this: Phys. Chem. Chem. Phys., 2020, 22, 18219

Received 15th June 2020

Accepted 4th August 2020

DOI: $10.1039 / \mathrm{d} 0 \mathrm{cp} 03208 \mathrm{e}$

rsc.li/pccp

\title{
Insight into the diffusion mechanism of sodium ion-polaron complexes in orthorhombic P2 layered cathode oxide $\mathrm{Na}_{x} \mathrm{MnO}_{2}$
}

\author{
Huu Duc Luong, (D) ${ }^{\text {ab }}$ Van An Dinh, (D) *cd Hiroyoshi Momida (D) ${ }^{\text {be }}$ and \\ Tamio Oguchi (iD *be
}

\begin{abstract}
Using the density functional theory, we investigated the geometric, electronic structure, phase stability and electrochemical properties of a potential $\mathrm{P} 2$ layer orthorhombic cathode material $\mathrm{Na}_{x} \mathrm{MnO}_{2}(0 \leq x \leq 1)$ applied for sodium-ion batteries. Herein, we shed the light on the undeniable effect of the polaron formation and polaron migration on the diffusion of $\mathrm{Na}^{+}$ions in the orthorhombic $\mathrm{P} 2$ layered oxides. Both $\mathrm{GGA}+\mathrm{U}$ and HSEO6 methods agree that, when a $\mathrm{Na}^{+}$ion is removed from the fully charged state of $\mathrm{NaMnO}_{2}$, the accompanying polaron preferably forms at one of the third nearest $\mathrm{Mn}(3 \mathrm{NN})$ octahedra to the $\mathrm{Na}$ vacancy, implying the oxidization of the $\mathrm{Mn}^{3+}$ ion at one of these $3 \mathrm{NN}$ sites to $\mathrm{Mn}^{4+}$. The positive polaron migrates simultaneously with the Na vacancy and would hinder the diffusion of $\mathrm{Na}$ ions. Two kinds of elementary diffusion processes, named parallel and crossing, have been explored which required almost same activation energy of about $423 \mathrm{meV}(518 \mathrm{meV})$ by GGA+U (HSE06). In the fully discharged state, GGA+U and HSEO6 methods indicate that the negative polaron forms at one of the second nearest $\mathrm{Mn}$ neighbours (2NN). The activation energy of $273 \mathrm{meV}$ (327 meV) is needed for diffusion in a structure with a low $\mathrm{Na}$ concentration, which is much lower than that required for diffusion in the $\mathrm{Na}$-rich regime. Consequently, $\mathrm{Na}^{+}$ions can diffuse easier at lower $\mathrm{Na}$ concentrations. With the overall activation energy of $423 \mathrm{meV}(518 \mathrm{meV})$, this material exhibits a faster ion diffusion in comparison with the prevailing lithium-based materials such as olivine phosphate.
\end{abstract}

\section{Introduction}

In recent decades, secondary lithium-ion batteries (LIBs) have emerged as crucial energy storage components of electronic portable devices and vehicles. ${ }^{1}$ However, the $\mathrm{Li}$ abundance is just $0.0017 \%$ of the Earth's crust. $^{2}$ With the ever-increasing energy demand and the limited availability of Li element in the Earth's crust, it has been predicted that the Li abundance will be inadequate to the raw materials consumption for the LIBs productions. As a consequence, it has been anticipated that the

\footnotetext{
${ }^{a}$ Department of Precision Science \& Technology and Applied Physics, Graduate School of Engineering, Osaka University, 2-1 Yamadaoka, Suita, Osaka, 565-0871, Japan

${ }^{b}$ Department of Theoretical Nanotechnology, Institute of Scientific and Industrial Research, Osaka University, Ibaraki, Osaka 567-0047, Japan.

E-mail: oguchi@sanken.osaka-u.ac.jp

${ }^{c}$ Nanotechnology Program, Vietnam-Japan University, National University of Hanoi, Luи Нии Phuoc Street, Nam Tu Liem District, 1000, Vietnam.

E-mail: dv.an@vju.ac.vn

${ }^{d}$ Centre of Atomistic and Molecular Technologies, Graduate School of Engineering, Osaka University, 2-1 Yamadaoka, Suita, Osaka 565-0871, Japan

${ }^{e}$ Elements Strategy Initiative for Catalysts and Batteries, Kyoto University, Kyoto, 615-8245, Japan
}

world's energy storage market would experience a quick upturn in LIBs' prices. In order to meet the highly increasing energy storage applications, several alternative elements such as $\mathrm{Na}, \mathrm{K}$, and $\mathrm{Mg}$, have been used as charge carriers in the ion batteries. Among them, $\mathrm{Na}$ element is well-known as possessing the innate electrochemical affinity with $\mathrm{Li}$, and recognized as the sixth order in the most plentiful elements, which contributes to $2.3 \%$ of the Earth's crust and $1.1 \%$ of the ocean. ${ }^{3}$ Therefore, sodium-based compounds have attracted a great deal of attention and expected to become the next generation of rechargeable batteries, named sodium-ion batteries (SIBs). Various materials such as NASICON, olivine phosphate, have been suggested to be promising candidates with similar electrochemical properties as $\mathrm{Li}$ analogous compounds. The apparent explanation is that sodium ions can diffuse easily inside the materials even though it possesses a larger ionic radius and atomic weight $\left(r_{\mathrm{Na}}=0.98 \AA\right.$, $\left.m_{\mathrm{Na}}=23 \mathrm{~g} \mathrm{~mol}^{-1}\right)$ compared with those of lithium $\left(r_{\mathrm{Li}}=0.69 \AA\right.$, $\left.m_{\mathrm{Li}}=6.9 \mathrm{~g} \mathrm{~mol}^{-1}\right) .4$

In structure, three indispensable components of any rechargeable batteries are cathode,$^{5-18}$ anode ${ }^{19,20}$ and electrolyte, ${ }^{21,22}$ in which the cathode primarily determines the overall cell voltage. Among the materials for cathode, layered oxides $\mathrm{A}_{x} \mathrm{MO}_{2}$ 
(where A stands for alkali metal with concentration of $x$, and $\mathrm{M}$ represents transition metals such as $\mathrm{Mn}, \mathrm{Fe}, \mathrm{Ni}$, and $\mathrm{Co}$ ) are in the spotlight as the most promising alternatives with high voltage (2.0-3.5 V) and capacity (150-210 $\left.\mathrm{mA} \mathrm{h} \mathrm{g}^{-1}\right)$ for both LIBs and SIBs. ${ }^{23-32}$ Among several types of layered oxides classified by Delmas et al., ${ }^{33} \mathrm{O} 3$ and P2 layered oxides, in which sodium ions locate at octahedral sites (denoted as $\mathrm{O}$ ) and prismatic sites (denoted as $\mathrm{P}$ ), respectively; the numbers 3 and 2 stand for the number of $\mathrm{MO}_{2}$ layers in a unit cell, are two most prevailing synthesized layered oxides groups. Although $\mathrm{O} 3$ layered oxides deliver a higher capacity, the better electrochemical performance with lower diffusion barrier and higher ionic conductivity was recorded in P2 layered oxides. ${ }^{34,35}$ In addition, $\mathrm{O} 3$ materials often exhibit hygroscopic property while P2 materials are more stable in ambient condition. ${ }^{36}$

Amid the P2 layered transition metals based oxides (Mn, Co, $\mathrm{Ni}$ ), the sodium manganese oxide $\mathrm{Na}_{\mathrm{x}} \mathrm{MnO}_{2}$ holds scientists spellbound more due to its cheaper cost and easier for synthesis. ${ }^{37-40}$ Two single-phase samples reported in experiments by slow cooling and quenching methods show hexagonal (space group $\mathrm{P}_{3} / m m c$, denoted by $\mathrm{P} 2$ ) and orthorhombic (space group $\mathrm{Cmcm}$, denoted by $\mathrm{P}^{\prime} 2$ ) phases. ${ }^{38}$ Both two phases exhibit a voltage window of 2.0-3.8 V. Even though the P2 phase samples exhibit a little higher cycle number (120 cycles), the $\mathrm{P}^{\prime} 2$ phase materials deliver a significantly higher specific capacity of $210 \mathrm{~mA} \mathrm{~h} \mathrm{~g}{ }^{-1}$ than the P2 phase $\left(140 \mathrm{~mA} \mathrm{~h} \mathrm{~g}{ }^{-1}\right) .{ }^{41-43}$ Since the concentration of $\mathrm{Na}$ reaches more than $0.67(x>0.67), \mathrm{P} 2$ layered phase shows a phase transformation to $\mathrm{P}^{\prime} 2$, while $\mathrm{P}^{\prime} 2$ layered material also experiences a phase transformation to OP4 at low concentration $(x<0.25) .{ }^{41}$ The phase transformation causes a rough discharging voltage profile over the capacity. An idea of doping other metals such as Fe, Co, Ni, Li, Mg, and $\mathrm{Zn}$, has been indicated in many previous experimental and theoretical investigations to improve the stability and obtain better electrochemical properties. ${ }^{44-47}$ Even though the smoother voltage lines have been reported, the phase transformation has been also observed in those doped materials. ${ }^{46,47}$ Although there are many investigations of layered oxides for cathode materials, the Jahn-Teller effect and diffusion mechanism have not been addressed clearly so that more profound investigations are essential to perform.

In previous reports, ${ }^{5,48-51}$ many scientists pointed out the importance of a quasi-particle, named small polaron, to the diffusion of $\mathrm{Li}^{+} / \mathrm{Na}^{+}$ion inside the transition-metal-based materials. The small polaron is formed due to the local distortion after the oxidation/reduction of transition metals. With a strong binding energy of $500 \mathrm{meV}$ between the alkali vacancy/ ion and the positive/negative polaron, ${ }^{48}$ the polaron migrates simultaneously with the diffusion of $\mathrm{Li} / \mathrm{Na}$ vacancy/ion, and the polaron migration generally lowers the diffusion of those charge carriers inside the materials. The arrangement of the geometric structure and the polaron effect are incontrovertible during charging/discharging processes and would be clearly depicted for a better diffusion prediction. Several types of elementary diffusion paths might require different activation energies. ${ }^{5}$ Herein, we present a comprehensive density functional theory (DFT) investigation of the geometrical and

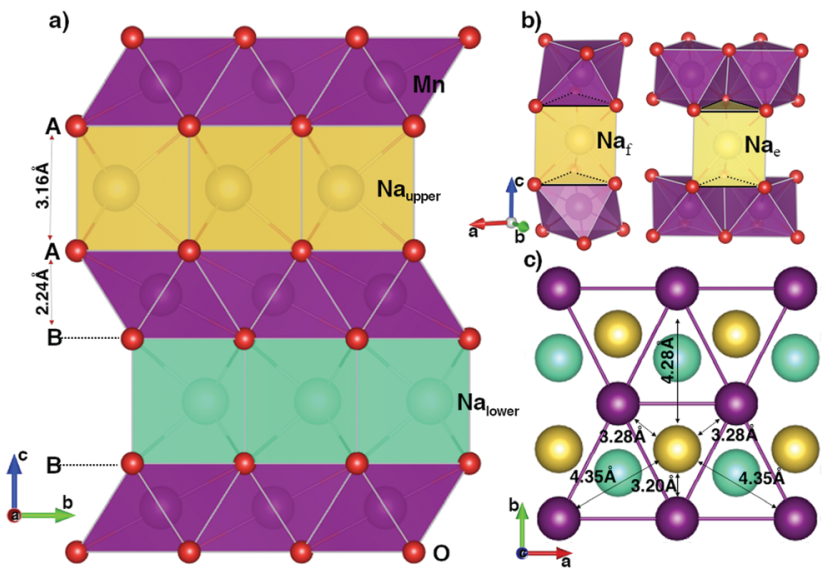

Fig. 1 The geometric structure of P2 orthorhombic $\mathrm{NaMnO}_{2}$. The violet, red, yellow and cyan balls stand for $\mathrm{Mn}, \mathrm{O}, \mathrm{Na}$ upper and $\mathrm{Na}$ lower atoms, respectively. The data is obtained from $G G A+U$ method.

electronic structures, the polaron formation and diffusion mechanism of $\mathrm{Na}$ ions. Especially, based on the model of polaron-Na ion/vacancy diffusion complex, we shed a light on how the Jahn-Teller polaron formation and polaron migration affect the diffusion of $\mathrm{Na}^{+}$ions inside the orthorhombic manganese layered oxides $\mathrm{Na}_{x} \mathrm{MnO}_{2}(0 \leq x \leq 1)$.

\section{Calculation schemes}

All DFT energy calculations were performed using the Vienna $\mathrm{Ab}$ initio Simulation Package (VASP) within the projector augmented wave (PAW) pseudopotentials. ${ }^{52}$ Spin polarized calculations were accomplished with an energy cutoff of $700 \mathrm{eV}$ and the $16 \times 8 \times 4 k$-point mesh for unit cell (4 formula units) and $4 \times 4 \times 2 k$-point mesh for $2 \times 1 \times 1$ supercell ( 8 formula units). Since the Perdew-Burke-Ernzerhof $(\mathrm{PBE})^{53}$ generalized gradient approximation (GGA) over-estimates the delocalization of $3 \mathrm{~d}$ orbitals of transition metals, hence fails in describing the small polaron formation, a Hubbard like term $U=4.0 \mathrm{eV}^{54}(\mathrm{GGA}+U)$ of the Dudarev ${ }^{55}$ scheme was added. The hybrid functional method HSE06 ${ }^{56}$ was also employed for comparison. Previously, DFT functionals combined with the van der Waals of vdW-D3 correction yield better agreement with the experimental results of the layered structure, ${ }^{57}$ thus the vdW interaction wdW-D3 correction scheme ${ }^{58}$ was introduced. The structure optimization calculations were converged until

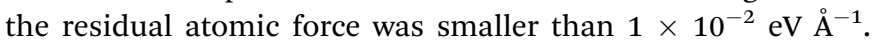
Structural stability, $\mathrm{Na}^{+}-\mathrm{Mn}^{3+}-\mathrm{Mn}^{4+}$ ordering, voltages, densities of states (DOS) and band structure were calculated by both GGA $+U$ and HSE06 methods.

The diffusion mechanism of $\mathrm{Na}^{+}$ion in the charging and discharging processes inside the $4 \times 2 \times 1$ (32 formula units) supercell was explored by using the nudged elastic band (NEB) approximation $^{59}$ employing both GGA $+U$ and HSE06 methods combined with vdW-D3 correction scheme. The spring force between images is set at $-5 \mathrm{eV}^{-1}$. The NEB calculation was converged when the residual force was smaller than $0.03 \mathrm{eV} \AA^{-1}$. 
Table 1 The lattice constants, $\mathrm{Mn}-\mathrm{O}$ bond lengths and magnetic moments in $\mathrm{Na}_{x} \mathrm{MnO}_{2}$ unit cell $(x=0,1)$

\begin{tabular}{|c|c|c|c|c|c|}
\hline & & \multicolumn{2}{|l|}{$\underline{\mathrm{MnO}_{2}}$} & \multicolumn{2}{|l|}{$\mathrm{NaMnO}_{2}$} \\
\hline & & $\mathrm{GGA}+U$ & HSE06 & $\mathrm{GGA}+U$ & HSE06 \\
\hline \multirow[t]{3}{*}{ Lattice constant $(\AA)$} & $a$ & 2.9595 & 2.8672 & 2.9414 & 2.8661 \\
\hline & $b$ & 5.1254 & 4.9574 & 5.7184 & 5.6007 \\
\hline & $c$ & 9.6246 & 9.5440 & 10.8204 & 10.6499 \\
\hline & 145.99 & 135.66 & 182.01 & 170.96 \\
\hline \multicolumn{2}{|l|}{ Mn-O bond $(\AA)$} & $1.96(\times 6)$ & $1.91(\times 6)$ & $\begin{array}{l}1.99(\times 4) \\
2.41(\times 2)\end{array}$ & $\begin{array}{l}1.94(\times 4) \\
2.37(\times 2)\end{array}$ \\
\hline \multicolumn{2}{|l|}{ Average $(\AA)$} & 1.96 & 1.91 & 2.13 & 2.08 \\
\hline \multicolumn{2}{|l|}{ Magnetic moment $\left(\mu_{\mathrm{B}}\right)$} & 3.229 & 3.032 & 3.856 & 3.734 \\
\hline
\end{tabular}

\section{Results and discussion}

\section{The crystal structure}

The geometric orthorhombic structure of $\mathrm{Na}_{x} \mathrm{MnO}_{2}(0 \leq x \leq 1)$ is shown in Fig. 1. In the unit cell, two $\mathrm{MnO}_{2}$ layers, formed by sharing six edges of each $\mathrm{MnO}_{6}$ octahedron with six nearest $\mathrm{MnO}_{6}$ octahedrons, contain four oxygen layers alternating an arrangement of A-B-B-A. In the full-unoccupied Na structure $\mathrm{MnO}_{2}(x=0)$, the GGA+U (HSE06) results, as shown in Table 1, indicate that each $\mathrm{Mn}$ ion is surrounded by six oxygen ions with a same bond length of $1.96 \AA$ ( $1.91 \AA)$ to create a regular $\mathrm{MnO}_{6}$ octahedron. The slab distance between two $\mathrm{MnO}_{2}$ layers is $2.88 \AA(2.88 \AA$ ̊̊).

Since $\mathrm{Na}^{+}$ions are inserted in an empty space between $\mathrm{MnO}_{2}$ layers, they create a sandwich-liked structure. As illustrates in Fig. 1b, sodium ions can locate at atomic environments of edgeshared prisms $\left(\mathrm{Na}_{\mathrm{e}}\right)$, where each $\mathrm{NaO}_{6}$ prism shares six edges of two bottom faces with six $\mathrm{MnO}_{6}$ octahedrons; or of face-shared prisms $\left(\mathrm{Na}_{\mathrm{f}}\right)$, in which $\mathrm{NaO}_{6}$ prism shares two bottom faces with two $\mathrm{MnO}_{6}$ octahedrons in upper and lower $\mathrm{MnO}_{2}$ layers. In the full Na-occupied sites, our DFT calculations point out that the $\mathrm{Na}^{+}$ions prefer locating at the $\mathrm{Na}_{\mathrm{e}}$ sites with the lower total energy of $220 \mathrm{meV}$ f.u. ${ }^{-1}$ than that at the $\mathrm{Na}_{\mathrm{f}}$ site. The insertion of Na atoms to the $\mathrm{MnO}_{2}$ layered structure also results in the reduction reaction of $\mathrm{Mn}^{4+}\left(\mathrm{d}^{3}\right)$ to $\mathrm{Mn}^{3+}\left(\mathrm{d}^{4}\right)$. As a result, both $\mathrm{GGA}+U$ and HSE06 methods unanimously witness a sizable elongation in the bond length of the $\mathrm{Mn}-\mathrm{O}$ bonds along the [010] direction from $1.96 \AA$ to $2.41 \AA$ by $\mathrm{GGA}+U$ (from $1.91 \AA$ to $2.37 \AA$ by HSE06), while four other bonds increase slightly. On average, the bond length increases by approximately $0.17 \AA$. In addition, the magnetic moments are $3.856 \mu_{\mathrm{B}}$ and $3.229 \mu_{\mathrm{B}}$ obtained by GGA $+U\left(3.734 \mu_{\mathrm{B}}\right.$ and $3.032 \mu_{\mathrm{B}}$ by HSE06) for $\mathrm{Mn}^{3+}$ and $\mathrm{Mn}^{4+}$ ions, respectively. The significant elongation in bond lengths along the [010] direction leads to the increase of the lattice constant $b$ by approximately $11.5 \%$ (13.0\%). Similarly, inserted positive $\mathrm{Na}^{+}$ions expand the distance between two $\mathrm{MnO}_{2}$ layers so that the lattice constant $c$ expands by about $12.4 \%(11.6 \%)$. In the case of all $\mathrm{Na}^{+}$ions fully intercalated, the volume of the unit cell increases $19.8 \%$ (20.6\%).

An important point is the distance relationship between each $\mathrm{Na}^{+}$ion and its nearest $\mathrm{Mn}^{3+}$ ions. The distances from each $\mathrm{Na}^{+}$ ion to the first, second, and third nearest $\mathrm{Mn}^{3+}$ neighbours (1NN, $2 \mathrm{NN}$ and $3 \mathrm{NN})$ are $3.28,4.35,4.82 \AA(3.22,4.26,4.72 \AA)$ obtained

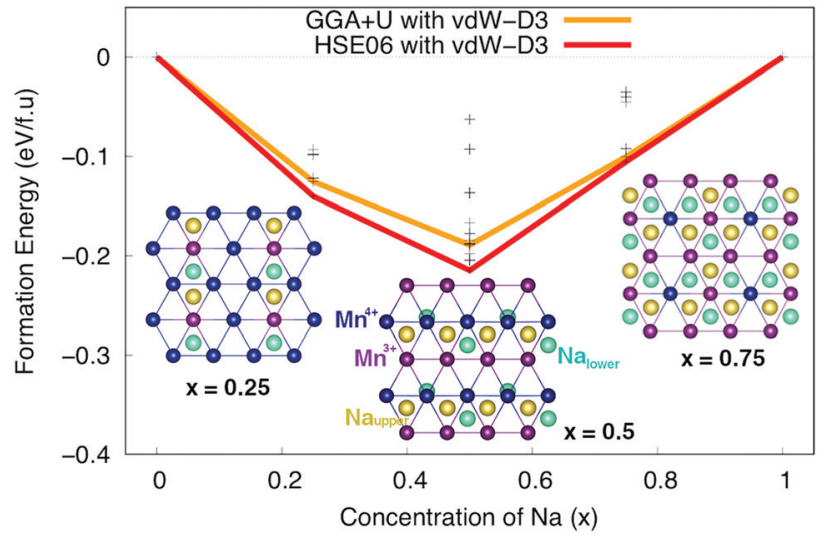

Fig. 2 The formation energy at $\mathrm{Na}$ concentrations of $x=0,0.25,0.50$, 0.75 and 1 of $\mathrm{P} 2$ orthorhombic $\mathrm{Na}_{x} \mathrm{MnO}_{2}$. Insets show the most stable structures at $x=0.25,0.50$ and 0.75 , where the violet, blue, yellow and cyan balls stand for $\mathrm{Mn}^{3+}, \mathrm{Mn}^{4+}, \mathrm{Na}_{\text {upper }}$ and $\mathrm{Na}_{\text {lower }}$ ions, respectively.

from GGA+U (HSE06) method, respectively. With the considerable difference in distance, the oxidation/reduction reactions of those Mn groups do not equivalently happen by their nearest $\mathrm{Na}^{+}$ ions deintercalation/intercalation.

\section{Phase stability and $\mathrm{Na}^{+}-\mathrm{Mn}^{3+}-\mathrm{Mn}^{4+}$ ordering}

Subsequently, $\mathrm{Na}^{+}-\mathrm{Mn}^{3+}-\mathrm{Mn}^{4+}$ ordering structures of $\mathrm{Na}$ different concentrations, phase stability and voltage were carefully considered. Nearly 100 configurations of different $\mathrm{Na}^{+}$ion concentrations $(x=0.25,0.50$, and 0.75$)$ were investigated. The formation energy $E$ can be estimated from the following formula:

$$
E=E_{\mathrm{Na}_{x} \mathrm{MnO}_{2}}-x E_{\mathrm{NaMnO}_{2}}-(1-x) E_{\mathrm{MnO}_{2}}
$$

where $E_{\mathrm{Na}_{x} \mathrm{MnO}_{2}} ; E_{\mathrm{NaMnO}_{2}} ; E_{\mathrm{MnO}_{2}}$ are total energy of the most stable structures $\mathrm{Na}_{x} \mathrm{MnO}_{2}, \mathrm{NaMnO}_{2}$ and $\mathrm{MnO}_{2}$, respectively, and $x$ is $\mathrm{Na}$ concentration. The $\mathrm{Na}^{+}-\mathrm{Mn}^{3+}-\mathrm{Mn}^{4+}$ ion ordering and formation energy are given in Fig. 2. From a glance at Fig. 2, the most stable structure is at $x=0.5$, in which $\mathrm{Mn}^{3+} / \mathrm{Mn}^{4+}$ ions prefer to make alternative $\mathrm{Mn}^{3+}-\mathrm{Mn}^{4+}$ line along the [100] direction, and $\mathrm{Na}^{+}$ions locate at both $\mathrm{Na}_{\mathrm{e}}$ and $\mathrm{Na}_{\mathrm{f}}$ sites with a ratio of $2: 1$ to create a zigzag line along [100] direction. At $x=0.25$ and 0.75 , the most stable structures are the ones in which all of the $\mathrm{Na}^{+}$ions locate at $\mathrm{Na}_{\mathrm{e}}$ sites. The $\mathrm{Mn}$ ions in the lower layer and their symmetrically equivalent $\mathrm{Mn}$ ions in the upper layer along [001] direction tends to be oxidized/reduced concurrently. Obviously, the stable orderings of $\mathrm{Na}^{+}$ions at different concentrations are related to orderings of $\mathrm{Mn}^{4+}-\mathrm{Mn}^{3+}$ ions in $\mathrm{MnO}_{2}$ layers.

\section{Electronic structure}

The density of states (DOS) and the band structures of the most stable structures of $\mathrm{Na}_{x} \mathrm{MnO}_{2}(x=0,0.25,0.50,0.75$ and 1$)$ are illustrated in Fig. 3. At $x=0$, both the valence band and conduction bands are mainly contributed by $2 \mathrm{p} \mathrm{O}$ states and $3 \mathrm{~d}$ Mn states. The states near the Fermi level come from $2 \mathrm{p}$ states dominantly. The estimated up/down-spin gap is $0.82 / 2.30 \mathrm{eV}$ $(2.72 / 3.10 \mathrm{eV})$ by GGA $+U$ (HSE06). Since $x=0.25,0.50$, and 0.75 , new peaks in the upper valence band of DOS, contributed 

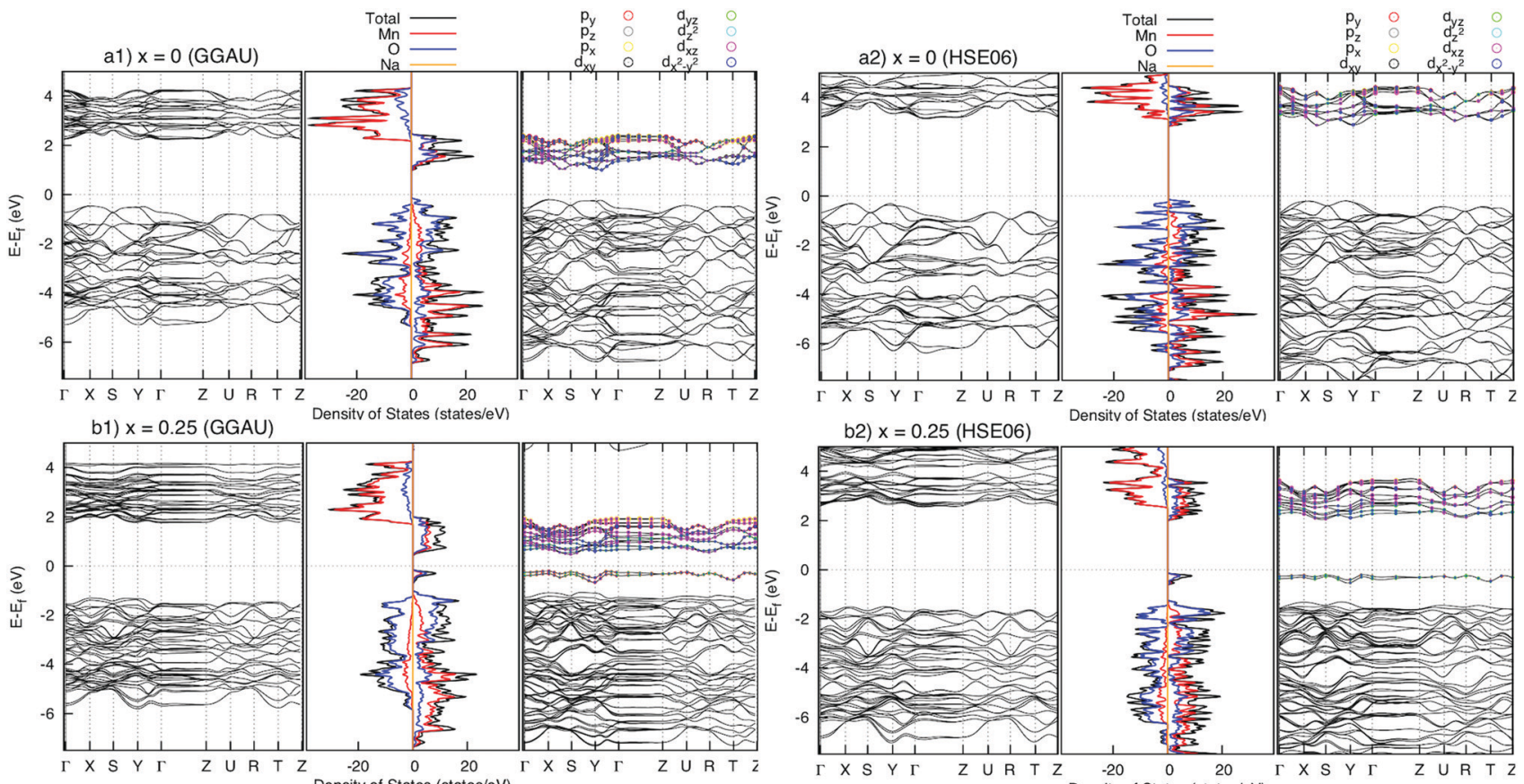

b2) $x=0.25$ (HSE06)

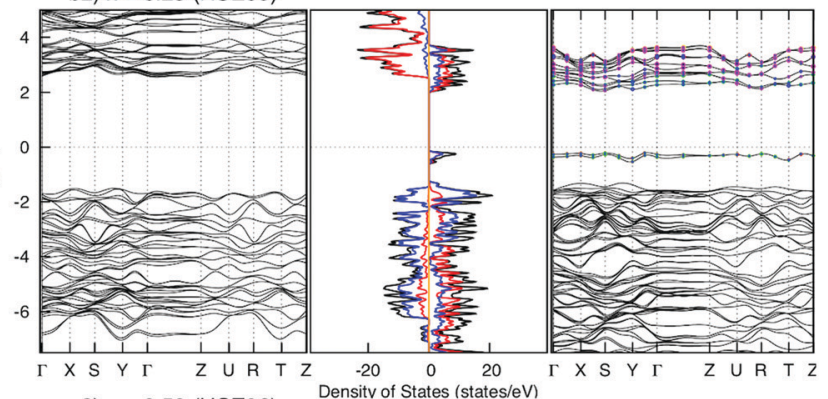

c1) $x=0.50$ (GGAU)

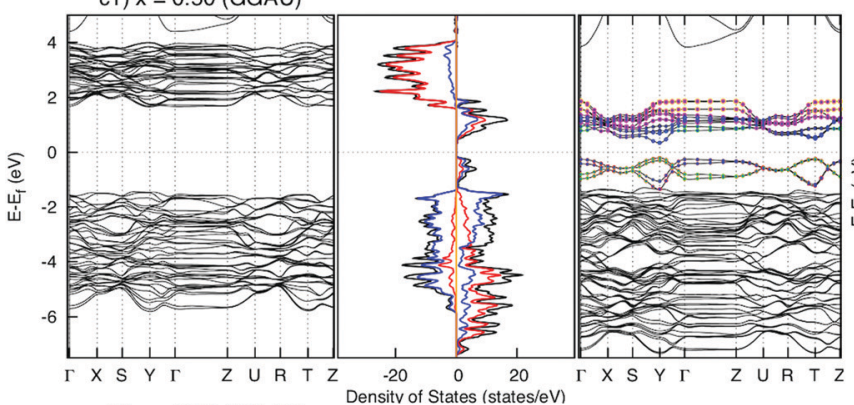

c2) $x=0.50$ (HSE06)

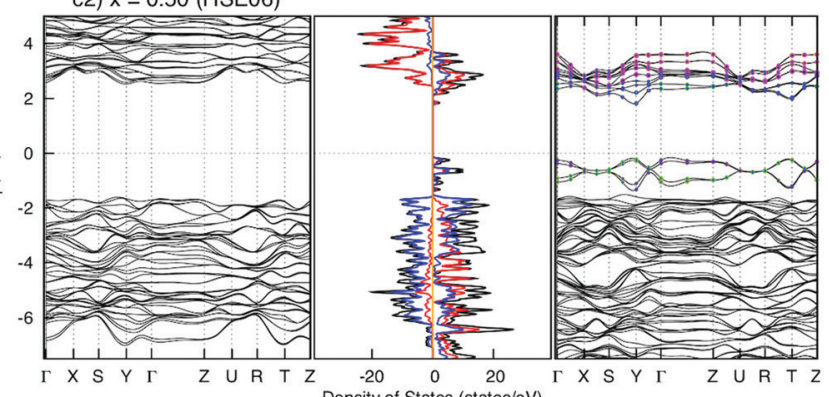

d2) $x=0.75$ (HSE06)
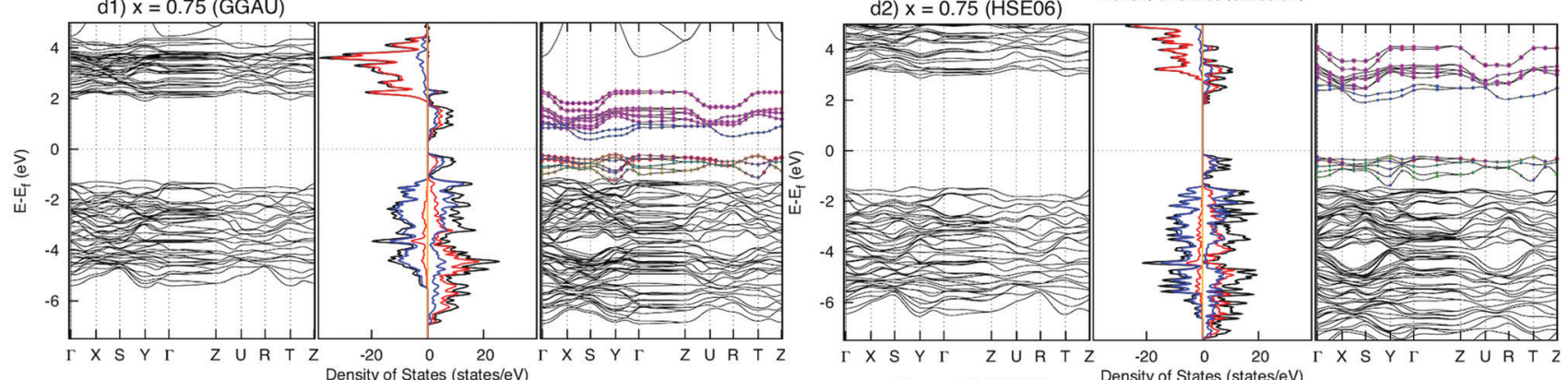

e1) $x=1$ (GGAU)
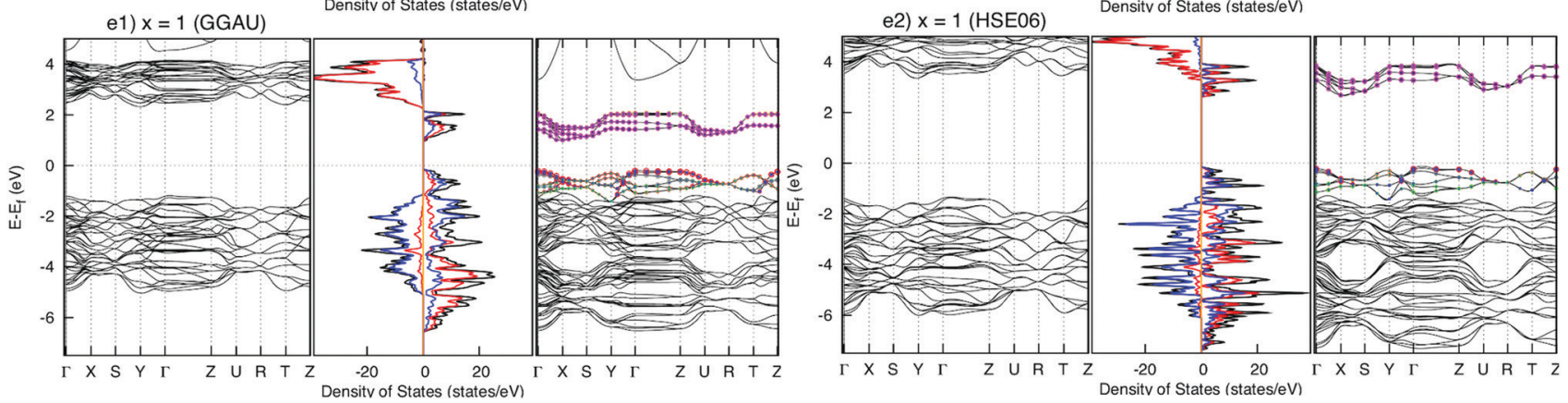

Fig. 3 Density of states (centre) and band structure of up-spin (right) and down-spin (left) of $\mathrm{Na}_{x} \mathrm{MnO}_{2}(x=0,0.25,0.50,075$, and 1). The energy origin is set to be the valence band top energy. 
Table 2 The bond lengths of $\mathrm{Mn}-\mathrm{O}$ at the $\mathrm{Mn}^{3 \mathrm{NN}} \mathrm{O}_{6}$ octahedron before and after single-Na deintercalation from the $\mathrm{NaMnO}_{2} 4 \times 2 \times 1$ supercell obtained by GGA+U (HSE06) method

\begin{tabular}{lllllll}
\hline $\mathrm{Mn}^{3 \mathrm{NN}}-\mathrm{O}$ & $\mathrm{O} 1$ & $\mathrm{O} 2$ & $\mathrm{O} 3$ & O4 & O5 & O6 \\
\hline Before & $1.99(1.94)$ & $1.99(1.94)$ & $1.99(1.94)$ & $1.99(1.94)$ & $2.41(2.37)$ & $2.41(2.37)$ \\
After & $1.97(1.91)$ & $1.97(1.91)$ & $1.97(1.92)$ & $1.97(1.92)$ & $2.03(1.96)$ & $2.10(2.03)$
\end{tabular}

mainly by a combination of $2 \mathrm{p}_{y} \mathrm{O}$ states with $3 \mathrm{~d}_{y z}$ and $3 \mathrm{~d}_{x^{2}-y^{2}}$ Mn states, appear next to the Fermi levels. From the GGA+U (HSE06) method, the up/down-spin gaps are shortened significantly to $0.25 / 2.66,0.14 / 2.68$, and $0.17 / 2.74 \mathrm{eV}(1.87 / 3.69$, $1.64 / 3.76$, and $1.71 / 3.91 \mathrm{eV}$ ), for $x=0.25,0.50$, and 0.75 , respectively. Obviously, during the intercalation/deintercalation processes, the band gap almost remains so that it likely keeps the electronic conductivity persist. At the concentration of $\mathrm{Na}^{+}$ ion of $x=1$, the $3 \mathrm{~d}_{x z}$ Mn states predominate the conduction band of $\mathrm{NaMnO}_{2}$ while the hybrid states of $2 \mathrm{p}_{y} \mathrm{O}$ states, $3 \mathrm{~d}_{y z}$ and $3 d_{x^{2}-y^{2}}$ Mn states hold the lion's share at states near Fermi level. The up/down-spin band gap estimated by GGA+ $U$ (HSE06) is enlarged to $0.81 / 3.11 \mathrm{eV}(2.48 / 4.31 \mathrm{eV})$, which is equivalent to those of full Na-unoccupied structure $(x=0)$. Understandably, the hybrid states of $2 \mathrm{p}_{y} \mathrm{O}$ states, $3 \mathrm{~d}_{y z}$ and $3 \mathrm{~d}_{x^{2}-y^{2}}$ Mn states play the crucial contribution to the electronic structure of the material.

\section{Voltage}

The calculated total energies of the most stable structures are used for voltage estimation. The voltage would be obtained by the formula below:

$$
V=-\frac{E_{\mathrm{Na}_{x_{1}} \mathrm{MnO}_{2}}-E_{\mathrm{Na}_{x_{2}} \mathrm{MnO}_{2}}-\left(x_{1}-x_{2}\right) E_{\mathrm{Na}}}{\left(x_{1}-x_{2}\right) e}
$$

where $E_{\mathrm{Na}_{x_{1}}} \mathrm{MnO}_{2} ; E_{\mathrm{Na}_{x_{2}} \mathrm{MnO}_{2}} ; E_{\mathrm{Na}}$ are total energy of $\mathrm{Na}_{x_{1}} \mathrm{MnO}_{2}$, $\mathrm{Na}_{x_{2}} \mathrm{MnO}_{2}$, Na metal, respectively. $x_{1}$ and $x_{2}$ are Na concentration corresponded to $\mathrm{Na}_{x_{1}} \mathrm{MnO}_{2}, \mathrm{Na}_{x_{2}} \mathrm{MnO}_{2}$. $e$ is the absolute electron charge. The GGA $U$ (HSE06) estimated voltages at specific capacities of 72,135 , and $191 \mathrm{~mA} \mathrm{~h} \mathrm{~g}^{-1}$ are 2.82, 2.60 , and $1.97 \mathrm{~V}(3.00,2.73$, and $1.99 \mathrm{~V})$, respectively. Those results are well-agreed with experimental results $(2.81,2.26$, and $1.86 \mathrm{~V}){ }^{45}$
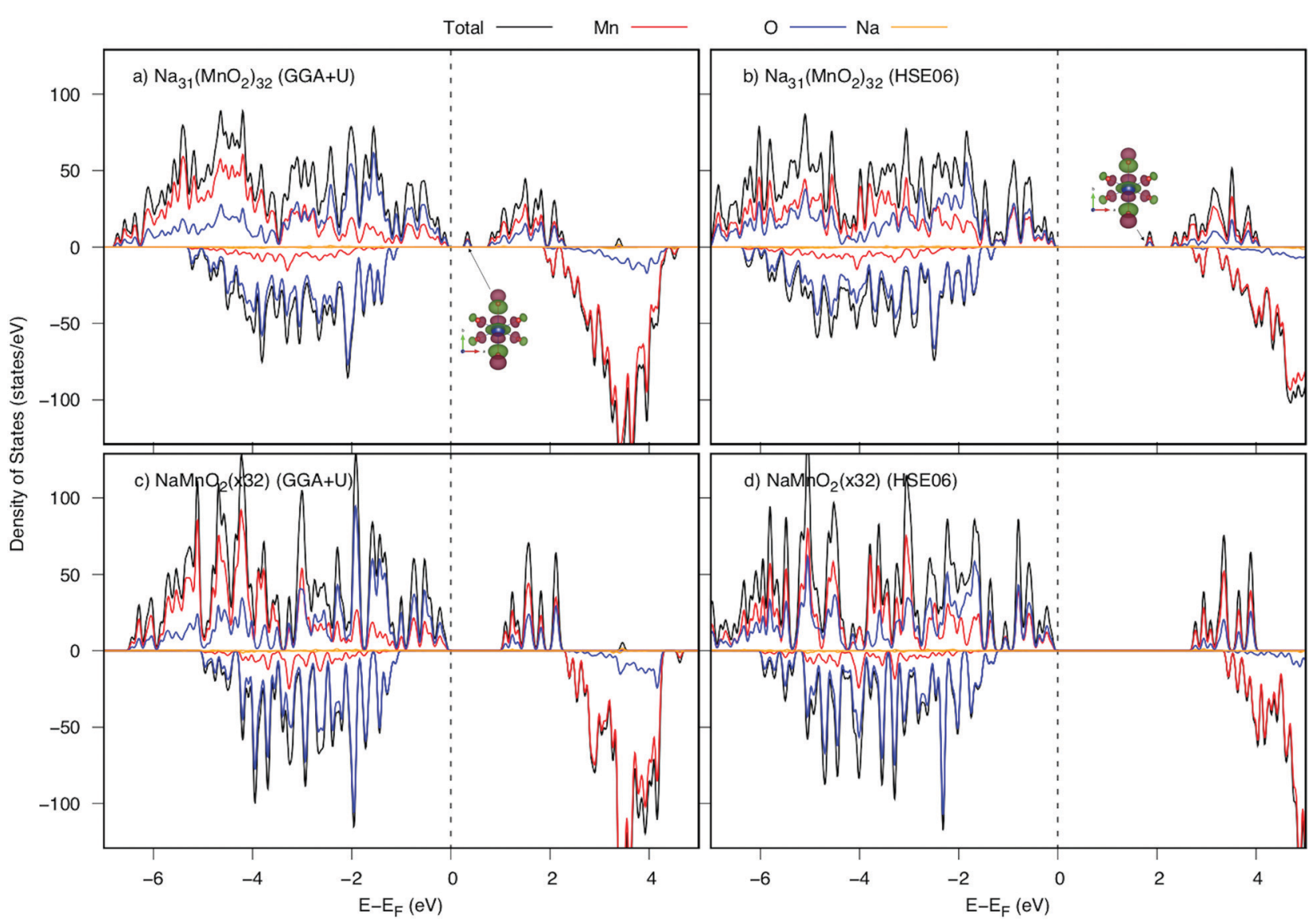

Fig. 4 Density of states of $\mathrm{Na}_{x} \mathrm{MnO}_{2}$ before and after one $\mathrm{Na}$ deintercalation from the $\mathrm{NaMnO}_{2}$ (32 f.u.) supercell calculated by GGA+U and HSE06. The valence band top is set to be the energy origin (vertical dashed lines). Insets show spatial electron distribution of the lowest unoccupied state at $\mathrm{Mn}^{3 \mathrm{NN}}$ sites indicated with arrows. 


\section{Diffusion at high Na concentration}

Now, we investigate the $\mathrm{Na}^{+}$diffusion mechanism in the full charging/discharging states. As discussed in the previous article, ${ }^{5}$ two factors, the so-called quasi-particle named small polaron and geometric arrangement of the framework structure, affect considerably to the diffusion mechanism. Several types of elementary diffusion processes were proposed, including single, parallel and crossing processes. In this work, we carefully analyzed the geometrical structure and polaron migration in the defect structures.

As a $\mathrm{Na}$ atom is deintercalated from the full-occupied $\mathrm{Na}$ structure, a positive hole is introduced to the structure. Surrounding the Na vacancy, there are six $1 \mathrm{NN}$, four $2 \mathrm{NN}$ and two $3 \mathrm{NN} \mathrm{Mn}^{3+}$ ions. Due to the hole introduced, one of those $\mathrm{Mn}^{3+}$ ions would be oxidized to be $\mathrm{Mn}^{4+}$. As a result, significant shrinkage of $\mathrm{Mn}-\mathrm{O}$ bonds at $\mathrm{Mn}$ site would be observed. Our DFT calculations indicate that the structure possessing a $3 \mathrm{NN}$ $\mathrm{Mn}^{3+}$ ion oxidized is the most stable one by its lowest energy (approximately $140 \mathrm{meV}$ lower than those of $1 \mathrm{NN}$ and $2 \mathrm{NN} \mathrm{Mn}$ sites). As shown in Table 2, at the $\mathrm{Mn}^{3 \mathrm{NN}} \mathrm{O}_{6}$ octahedron, two Mn-O5 and Mn-O6 bond lengths along [010] direction significantly decrease from $2.41 \AA(2.37 \AA)$ to $2.07 \AA$ and $2.10 \AA(1.96 \AA$ and $2.03 \AA$ ) after Na deintercalation. Overal, the average bond length is shrunk by approximately $0.13 \AA(0.12 \AA)$. Thereby, the magnetic moment at $3 \mathrm{NN}$ site reduces from 3.852 to $3.299 \mu_{\mathrm{B}}$ by GGA $+U$ (3.734 to $3.056 \mu_{\mathrm{B}}$ by HSE06). The considerable shortened $\mathrm{Mn}-\mathrm{O}$ bond length along the [010] direction results in a significant change in electronic structure. The DOSs of the structures before and after a $\mathrm{Na}$ deintercalation are shown in Fig. 4. Compared DOSs of those structures, it is understandable that the newborn bound state appearing right after the Fermi level is contributed mainly by a combination of O's $2 \mathrm{p}_{y}$ states with Mn's $3 \mathrm{~d}_{y z}$ and $3 \mathrm{~d}_{x^{2}-y^{2}}$ states. The $\mathrm{Mn}^{4+}$ ion at $3 \mathrm{NN}$ sites surrounded by $\mathrm{Mn}^{3+}$ ions creates a defect structure in which a local polarized distortion prefers to appear around 3NN sites. It is concluded that a positive polaron is formed at one of the 3NN Mn sites.

The positive polaron binds to the $\mathrm{Na}$ vacancy to form a $\mathrm{Na}$ vacancy-positive polaron complex. In the layer structure with the arrangement of $\mathrm{MnO}_{6}$ octahedron as shown in Fig. 1, the single process, which often requires the lowest activation energy, can not occur. Two types of elementary diffusion processes along the [010] direction were explored as shown in Fig. 5.

(i) The crossing process occurs if the positive polaron hops between the adjacent $\mathrm{MnO}_{2}$ layers. As illustrated in Fig. 5a, polaron leaps from the $\mathrm{MnO}_{2}$ lower layer to the upper one; explicitly from $\mathrm{Mn}_{\mathrm{A}}$ to its $\mathrm{Mn}$ neighbour $\mathrm{Mn}_{\mathrm{B}}$ while $\mathrm{Na}$ vacancy moves from an edged-share site $\mathrm{V}_{\mathrm{eA}}$ to another edged-shared site $\mathrm{V}_{\mathrm{eB}}$. The reaction coordinate of this process is $3.264 \AA$ by GGA+ $U$ (3.55 A by HSE06).

(ii) On the other hand, the parallel process occurs if the positive polaron jumps inside the $\mathrm{MnO}_{2}$ layer; explicitly from $\mathrm{Mn}_{\mathrm{C}}$ to $\mathrm{Mn}_{\mathrm{B}}$ while the Na vacancy diffuses from an edged-share site $\mathrm{V}_{\mathrm{eA}}$ to another edged-shared site $\mathrm{V}_{\mathrm{eB}}$ as shown in Fig. $5 \mathrm{~b}$. The reaction coordinate is $3.30 \AA$ by GGA $+U$ (3.41 $\AA$ by HSE06).

The activation energy profiles obtained from GGA $+U$ and HSE06 methods are shown in Fig. $5 c$ and d. Both the GGA+U and HSE06 methods give the result indicating that the parallel
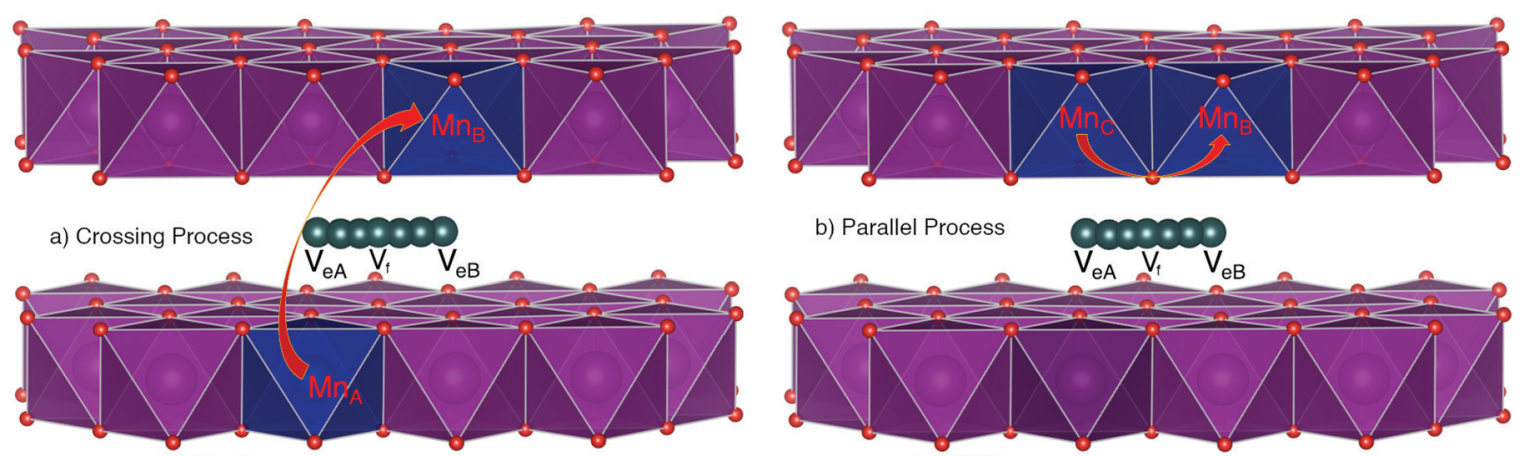

c) $\mathrm{GGA}+\mathrm{U}$

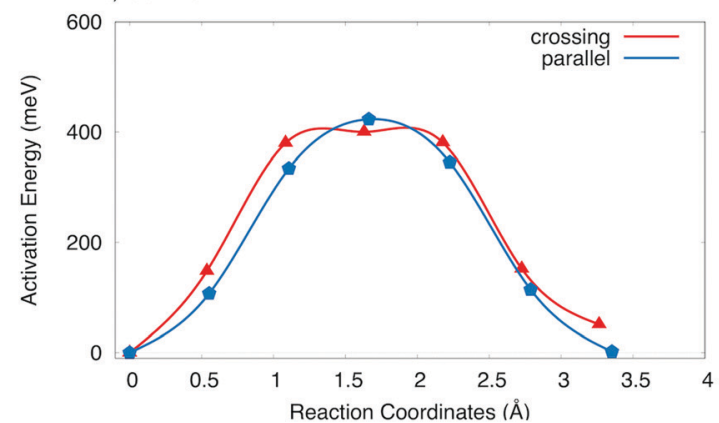

d) HSE06

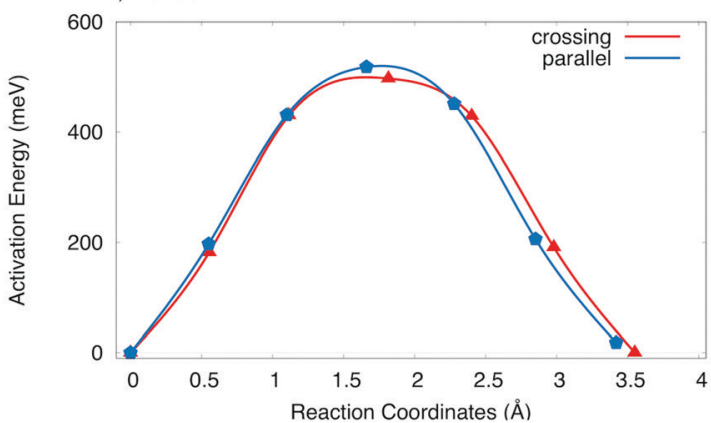

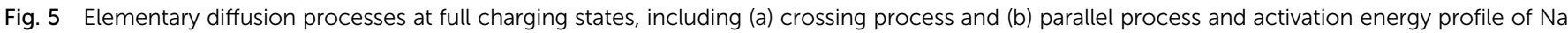

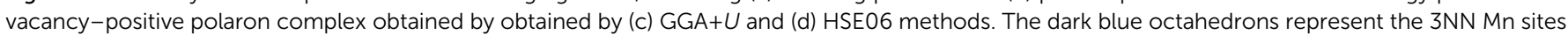
where polaron could be formed, and the dark cyan balls stand for Na vacancy trace diffusion. The other Na atoms are hidden for more clarification. 
Table 3 The bond lengths of $\mathrm{Mn}-\mathrm{O}$ at the $\mathrm{Mn}^{2 \mathrm{NN}} \mathrm{O}_{6}$ octahedron before and after a single $\mathrm{Na}$ intercalation into $\mathrm{MnO}_{2}$ supercell obtained by $\mathrm{GGA}+\mathrm{U}$ (HSE06) method

\begin{tabular}{llllllll}
\hline $\mathrm{Mn}^{3 \mathrm{NN}}-\mathrm{O}$ & $\mathrm{O} 1$ & $\mathrm{O} 2$ & $\mathrm{O} 3$ & O4 & O5 & O6 \\
\hline Before & $1.96(1.91)$ & $1.96(1.91)$ & $1.96(1.91)$ & $1.96(1.91)$ & $1.96(1.91)$ & $1.96(2.91)$ & $1.96(1.91)$ \\
After & $1.98(1.93)$ & $1.98(1.93)$ & $1.99(1.94)$ & $1.99(1.94)$ & $2.07(2.12)$ & $2.10(2.13)$ & $2.02(2.00)$
\end{tabular}

process requires a little higher activation energy than crossing one; they are $423 \mathrm{meV}$ and $400 \mathrm{meV}$ by GGA $+U$ (518 $\mathrm{meV}$ and $497 \mathrm{meV}$ by HSE06) for the parallel and the crossing processes, respectively. The path from edged-shared vacancy site to its neighbour edged-share vacancy site $\left(\mathrm{V}_{\mathrm{e}}-\mathrm{V}_{\mathrm{e}}\right)$ would be a sum of two sub-paths: the edge-shared vacant site to the face-shared vacant site $\left(\mathrm{V}_{\mathrm{e}}-\mathrm{V}_{\mathrm{f}}\right)$ and then the face-shared vacant site to the edge-shared vacant site $\left(\mathrm{V}_{\mathrm{f}}-\mathrm{V}_{\mathrm{e}}\right)$. With a scrap of difference, both parallel and crossing processes equivalently occur. Consequently, the overall activation energy is $423 \mathrm{meV}$ ( $518 \mathrm{meV}$ ) obtained by GGA $+U$ (and by HSE06). The influence of the positive polaron migration on the different diffusion paths of $\mathrm{Na}$ ion is equivalent.

\section{Diffusion at low Na concentration}

Next, we depict the fully discharged state. After the intercalation of the $\mathrm{Na}$ atom to $\mathrm{MnO}_{2}$ layered structure, an electron is also introduced to the structure to make a reduction reaction of
$\mathrm{Mn}^{4+}$ to $\mathrm{Mn}^{3+}$. Because of creating from almost perfect $\mathrm{MnO}_{6}$ octahedrons, the $\mathrm{Na}^{+}$ion is surrounded by six $1 \mathrm{NN}$ and six $2 \mathrm{NN}$ Mn ions. Among those, the Mn ion at the 2NN site prefers to be reduced first. As shown in Table 3, both GGA $U$ and HSE06 methods agree that there is a significant elongation in the average Mn-O bond length from $1.96 \AA$ (1.91 $\AA)$ to $2.02 \AA$ ( $2.00 \AA)$ by GGA $+U$ (HSE06), along with an increase magnetic moment from $3.299 \mu_{\mathrm{B}}\left(3.056 \mu_{\mathrm{B}}\right)$ to $3.856 \mu_{\mathrm{B}}\left(3.734 \mu_{\mathrm{B}}\right)$ by GGA $+U$ (HSE06). That implies the $\mathrm{Mn}^{4+}$ ion at $2 \mathrm{NN}$ sites would be reduced first to be $\mathrm{Mn}^{3+}$ ion. The change in the bond length results in a new peak appeared right next to the Fermi level in DOS as shown in Fig. 6. This bound state comes from a hybrid orbital predominantly of O's $2 p_{y}$ states and Mn's $3 \mathrm{~d}_{y z}$ and $3 \mathrm{~d}_{x^{2}-y^{2}}$ states. As different as in the fully charged state, a negative small polaron is formed at the 2NN Mn site.

Since the negative polaron arises in the Na inserted structure, two elementary diffusion processes, including parallel and
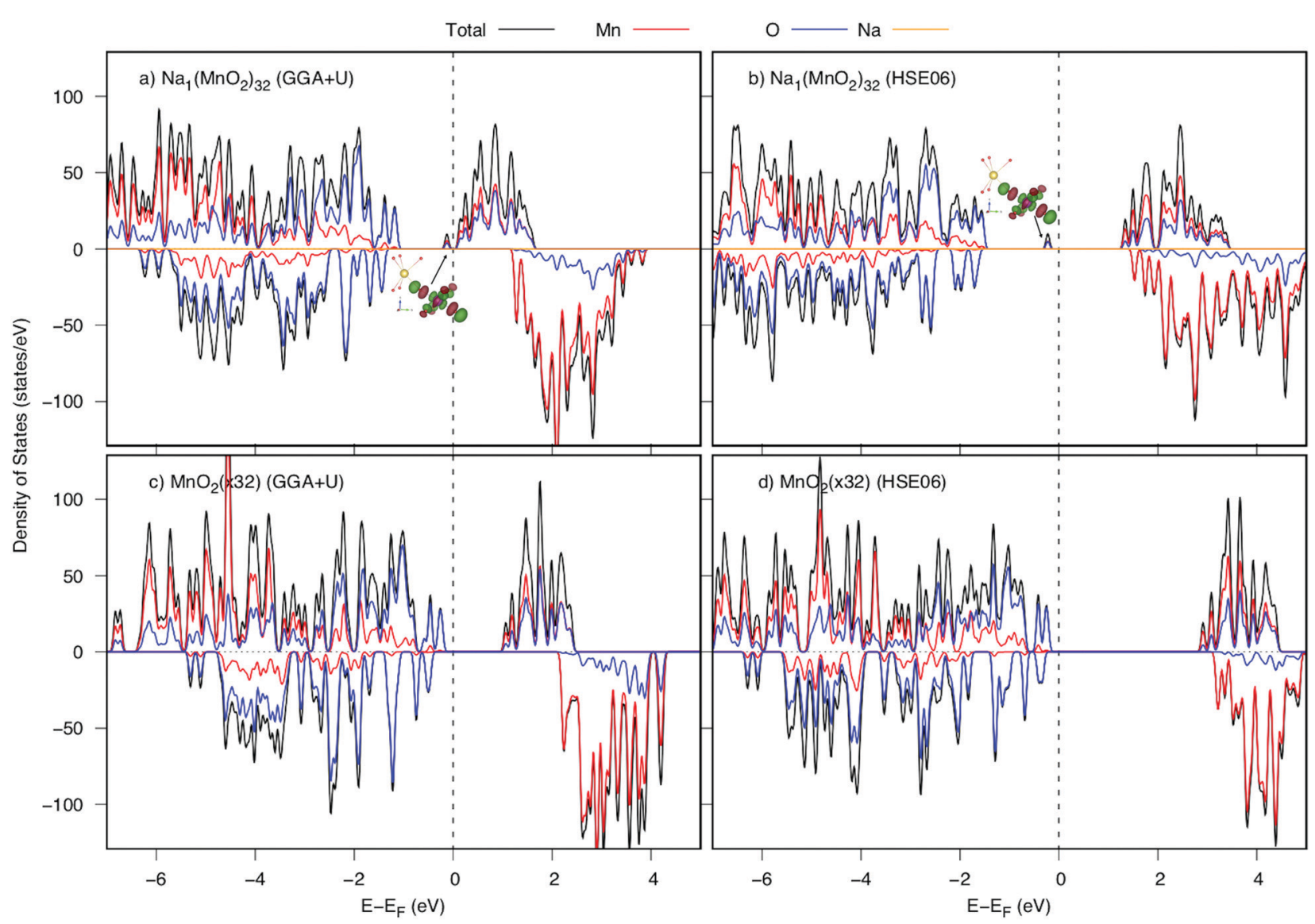

Fig. 6 Density of states of $\mathrm{Na}_{x} \mathrm{MnO}_{2}$ before and after a $\mathrm{Na}$ intercalation into the $\mathrm{MnO}_{2}$ (32 f.u.) supercell calculated by GGA+U and HSE06. The valence band top is set to be the energy origin (vertical dashed lines). Insets show spatial electron distributions of the highest occuppied states at the $\mathrm{Mn}^{2 \mathrm{NN}}$ sites indicated with arrows. 


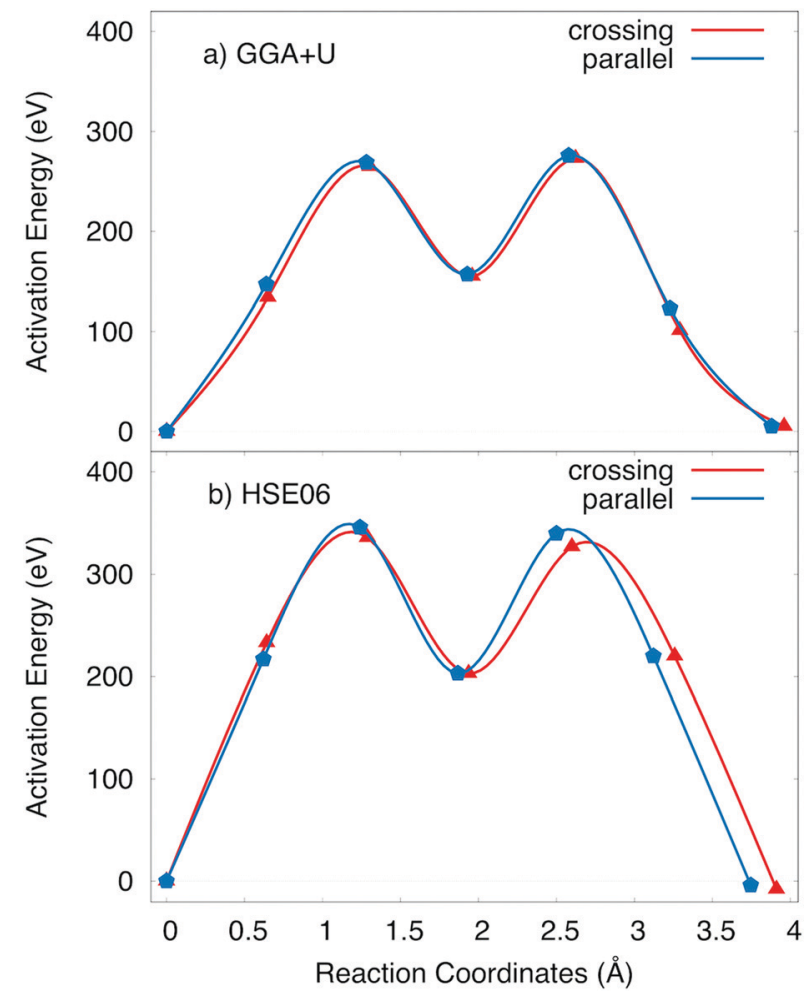

Fig. 7 Activation energy profile of $\mathrm{Na}^{+}$ion-negative polaron complex obtained by (a) GGA+U and (b) HSE06 method.

crossing processes, of $\mathrm{Na}^{+}$ion-negative polaron complexes were explored by employing the GGA $U$ and HSE06 methods in NEB calculations. As illustrated in Fig. 7, both GGA+U and HSE06 methods agree that the activation energies are almost same for the parallel and crossing processes, which also points toward that the effect of small polaron hopping might be analogous. Obviously, both parallel and crossing processes equivalently occurred. Similar to the Na vacancy diffusion at high Na concentration, the $\mathrm{Na}_{\mathrm{e}}-\mathrm{Na}_{\mathrm{e}}$ path is also a combination of the two small paths $\mathrm{Na}_{\mathrm{e}}-\mathrm{Na}_{\mathrm{f}}$ and $\mathrm{Na}_{\mathrm{f}}-\mathrm{Na}_{\mathrm{e}}$. Evidently, the $\mathrm{Na}_{\mathrm{f}}$ site is the metastable position of $\mathrm{Na}^{+}$ion. Two summits in the activation energy profile correspond to $\mathrm{Na}^{+}$positions at the intermediate place between $\mathrm{Na}_{\mathrm{e}}$ site and $\mathrm{Na}_{\mathrm{f}}$ site. The barriers estimated by GGA+U and HSE06 methods are 273 and $327 \mathrm{meV}$, respectively.

Overall, the energy required for Na diffusion is in the range from $273 \mathrm{meV}$ (327 meV) to $423 \mathrm{meV}$ (518 meV) during the charging/discharging process by GGA $+U$ (HSE06). Both parallel and crossing processes require an approximately same activation energy. Unlike polyanion cathode materials,${ }^{5-10}$ the effect of polaron migration to overall activation energy is insignificant so that it benefits the diffusion of $\mathrm{Na}$ vacancy/ion inside the cathode material. Polaron can jump in the plane of $\mathrm{MnO}_{2}$ layer, or jump interplane from the upper layer to lower layer or contrariwise required an equivalent energy. Consequently, both processes might occur during the diffusion of $\mathrm{Na}^{+}$ion inside the material. Compared with other common materials such as olivine phosphate $\left(\mathrm{LiFePO}_{4}\right)$ with an activation energy of $630 \mathrm{meV},{ }^{5}$ it is obvious that the activation energy of the orthorhombic P2 layered $\mathrm{Na}_{x} \mathrm{MnO}_{2}$ is considerably smaller, which benefits the $\mathrm{Na}^{+}$diffusion.

\section{Conclusions}

For the sake of brevity, the crystal and electronic structures, stability diagram, voltage as well as diffusion of Na vacancy/ ion-polaron complex in an auspicious cathode material $\mathrm{Na}_{x} \mathrm{MnO}_{2}$ $(0 \leq x \leq 1)$ were dissected using GGA+U and HSE06 methods. The most stable structures having different concentrations of $\mathrm{Na}$ were explored. At high or low Na concentrations, $\mathrm{Na}^{+}$ions prefer locating only at the edge-shared prism. The material is more stable at $x=0.5$. During the charging/discharging process, a conspicuous change in lattice constant $b$ and volume would be observed due to the significant shrinkage/elongation of bonds along the [010] direction. As a result, the hybrid orbital, combined by O's $2 p_{y}$ states, Mn's $3 \mathrm{~d}_{y z}$ and $3 \mathrm{~d}_{x^{2}-y^{2}}$ states, plays a crucial pivot in the electronic structure of the material during the intercalation/ deintercalation. Also, the electric conductivity is better at the intermediate structures. The voltages against capacity obtained from the most stable structures using GGA $U$ and HSE06 methods are well-agreed with the experimental result. When a $\mathrm{Na}^{+}$ion is deintercalated from the full-occupied Na structure, the positive small polaron is formed at one of the third nearest neighbours $\mathrm{Mn}$ to the Na vacancy. The polaron simultaneously escorts and would hinder the Na vacancy diffusion. Two elementary diffusion processes, including parallel and crossing process would occur equivalently and require an activation energy of $423 \mathrm{meV}(518 \mathrm{meV}$ ) by GGA+U (HSE06). In the fully discharged state, the insertion of $\mathrm{Na}^{+}$ion leads to the formation of a negative small polaron. Without $\mathrm{Na}^{+}-\mathrm{Na}^{+}$repulsion, the significantly lower activation energy of $273 \mathrm{meV}$ ( $327 \mathrm{meV}$ ) by GGA $+U$ (HSE06) is required. At low $\mathrm{Na}$ concentration regime, $\mathrm{Na}^{+}$ions can diffuse easier than at high Na concentration ones. Unlike polyanion based materials, the effect of polaron hopping is equivalent on the different diffusion paths in $\mathrm{Na}_{x} \mathrm{MnO}_{2}$. Compared to olivine phosphate, the $\mathrm{Na}^{+}$ion would diffuse in $\mathrm{Na}_{x} \mathrm{MnO}_{2}$ better than in polyanion framework like $\mathrm{LiFePO}_{4}$.

\section{Conflicts of interest}

There are no conflicts to declare.

\section{Acknowledgements}

This work was supported by the Japanese Government Scholarship from the Ministry of Education, Culture, Sports, Science and Technology (MEXT), Japan and the ESICB project of MEXT, Japan. The numerical calculations of this work were performed using Supercomputer at the Institute for Solid State Physics, University of Tokyo.

\section{Notes and references}

1 J. M. Tarascon and M. Armand, Nature, 2001, 414, 359. 
2 N. Yabuuchi, K. Kubota, M. Dahbi and S. Komaba, Chem. Rev., 2014, 114, 11636.

3 Q. Sun, Y. Yang and Z.-W. Fu, Electrochem. Commun., 2012, 16, 22.

4 V. Palomares, P. Serras, I. Villaluenga, K. B. Hueso, J. C. Gonzálezb and T. Rojo, Energy Environ. Sci., 2012, 5,5884 .

5 V. A. Dinh, J. Nara and T. Ohno, Appl. Phys. Express, 2012, 5, 045801.

6 K. M. Bui, V. A. Dinh and T. Ohno, Appl. Phys. Express, 2012, 5, 125802.

7 K. M. Bui, V. A. Dinh and T. Ohno, J. Phys.: Conf. Ser., 2013, 454, 012061.

8 D. M. Duong, V. A. Dinh and T. Ohno, Appl. Phys. Express, 2013, 6, 115801.

9 K. M. Bui, V. A. Dinh, S. Okada and T. Ohno, Phys. Chem. Chem. Phys., 2015, 17, 30433.

10 K. M. Bui, V. A. Dinh, S. Okada and T. Ohno, Phys. Chem. Chem. Phys., 2016, 18, 27226.

11 A. Kitajou, Y. Ishado, T. Yamashita, H. Momida, T. Oguchi and S. Okada, Electrochim. Acta, 2017, 245, 424.

12 M. Debbichi, L. Debbichi, V. A. Dinh and S. Lebe'gue, J. Phys. D: Appl. Phys., 2017, 50, 045502.

13 M. Hamaguchi, H. Momida and T. Oguchi, J. Phys. Soc. Jpn., 2018, 87, 044805.

14 H. D. Luong, T. D. Pham, Y. Morikawa, Y. Shibutani and V. A. Dinh, Phys. Chem. Chem. Phys., 2018, 20, 23625.

15 A. Kitajou, H. Momida, T. Yamashita, T. Oguchi and S. Okada, ACS Appl. Energy Mater., 2019, 2, 5968.

16 H. Kotaka, H. Momida, A. Kitajou, S. Okada and T. Oguchi, Chem. Rec., 2019, 19, 811.

17 M. Hamaguchi, H. Momida and T. Oguchi, Electrochim. Acta, 2020, 330, 135286.

18 H. Momida, A. Kitajou, S. Okada and T. Oguchi, J. Phys. Soc. Jpn., 2019, 88, 124709.

19 T. Yamashita, H. Momida and T. Oguchi, Electrochim. Acta, 2016, 195, 1.

20 T. D. Pham, H. D. Luong, K. Sato, Y. Shibutani and V. A. Dinh, Phys. Chem. Chem. Phys., 2019, 21, 24326.

21 K. M. Abraham and Z. Jiang, J. Electrochem. Soc., 1996, 143, 1.

22 K. M. Bui, V. A. Dinh, S. Okada and T. Ohno, Phys. Chem. Chem. Phys., 2016, 18, 27226.

23 S. P. Ong, V. L. Chevrier, G. Hautier, A. Jain, C. Moore, S. Kim, X. Ma and G. Ceder, Energy Environ. Sci., 2011, 4, 3680 .

24 N. Ortiz-Vitoriano, N. E. Drewett, E. Gonzaloa and T. Rojo, Energy Environ. Sci., 2017, 10, 1051.

25 N. Yabuuchi, H. Yoshida and S. Komaba, Electrochemistry, 2012, 80, 716.

26 S. Komaba, N. Yabuuchi, T. Nakayama, A. Ogata, T. Ishikawa and I. Nakai, Inorg. Chem., 2012, 51, 6211.

27 K. Takada, H. Sakurai, E. Takayama-Muromachi, F. Izumi, R. A. Dilanian and T. Sasaki, Nature, 2003, 422, 53.

28 J. Deng, W.-B. Luo, X. Lu, Q. Yao, Z. Wang, H.-K. Liu, H. Zhou and S.-X. Dou, Adv. Energy Mater., 2018, 8, 1701610.
29 K. Kubota, T. Asari, H. Yoshida, N. Yabuuchi, H. Shiiba, M. Nakayama and S. Komaba, Adv. Funct. Mater., 2016, 26, 6047.

30 F. Schipper, E. M. Erickson, C. Erik, J.-Y. Shin, F. F. Chesneau and D. Aurbach, J. Electrochem. Soc., 2017, 164, A6220.

31 K. Kubota, S. Kumakura, Y. Yoda, K. Kuroki and S. Komaba, Adv. Energy Mater., 2018, 8, 1703415.

32 R. J. Clement, P. G. Bruce and C. P. Grey, J. Electrochem. Soc., 2015, 162, A2589.

33 C. Delmas, C. Fouassier and P. Hagenmuller, Physica $B+C$, 1980, 99, 81.

34 M. H. Han, E. Gonzalo, G. Singh and T. A. Rojo, Energy Environ. Sci., 2015, 8, 81.

35 N. Yabuuchi, M. Kajiyama, J. Iwatate, H. Nishikawa, S. Hitomi, R. Okyuyama, R. Usui, Y. Yamada and S. Kobama, Nat. Mater., 2012, 11, 512.

36 J. Billaud, R. J. Clément, A. R. Amstrong, J. C. Vázquez, P. Rozier, C. P. Grey and P. G. Bruce, J. Am. Chem. Soc., 2014, 136, 17243.

37 N. Yabuuchi, M. Kajiyama, J. Iwatate, H. Nishikawa, S. Hitomi, R. Okuyama, R. Usui, Y. Yamada and S. Komaba, Nat. Mater., 2012, 11, 512.

38 J. Billaud, G. Singh, A. R. Amstrong, E. Gonzalo, V. Roddatis, M. Armand, T. Rojo and P. G. Bruce, Energy Environ. Sci., 2014, 7, 1387.

39 Q. Liu, Z. Hu, M. Chen, C. Zou, H. Jin, S. Wang, S.-L. Chou and S.-H. Dou, Small, 2019, 15, 1805381.

40 K. Zhang, D. Kim, Z. Hu, M. Park, G. Noh, Y. Yang, J. Zhang, V. W. Lau, S.-L. Chou, M. Cho, S.-Y. Choi and Y.-M. Kang, Nat. Commun., 2019, 10, 5302.

41 A. Caballero, L. Hernán, J. Morales, L. Sánchez, J. S. Pena and M. A. G. Aranda, J. Mater. Chem., 2002, 12, 1142.

42 S. Kumakura, Y. Tahara, K. Kubota, K. Chihara and S. Komaba, Angew. Chem., Int. Ed., 2016, 55, 12760.

43 M.-S. Kwon, S. G. Lim, Y. Park, S.-M. Lee, K. Y. Chung, T. J. Shin and K. T. Lee, ACS Appl. Mater. Interfaces, 2017, 9, 14758.

44 S. Kumakura, Y. Tahara, S. Sato, K. Kubota and S. Komaba, Chem. Mater., 2017, 29, 8958.

45 J.-Y. Hwang, J. Kim, T.-Y. Yu and Y.-K. Sun, Adv. Energy Mater., 2019, 9, 1803346.

46 Y.-J. Park, J. U. Choi, J. H. Jo, C.-H. Jo, J. Kim and S.-T. Myung, Adv. Funct. Mater., 2019, 29, 1901912.

47 J. U. Choi, C. S. Yoon, Q. Zhang, P. Kaghazchi, Y. H. Jung, K.-S. Lee, D.-C. Anh, Y.-K. Sun and S.-T. Myung, J. Mater. Chem. A, 2019, 7, 202.

48 T. Maxisch, F. Zhou and G. Ceder, Phys. Rev. B: Condens. Matter Mater. Phys., 2006, 73, 104301.

49 T. L. Tran, H. D. Luong, D. M. Duong, N. T. Dinh and V. A. Dinh, ACS Omega, 2020, 5(10), 5429.

50 L. Zheng, Z. Wang, M. Wu, B. Xu and C. Ouyang, J. Mater. Chem. A, 2019, 7, 6053.

51 Z. Zhu, H. Peelaers and C. G. Van de Walle, Chem. Mater., 2019, 31, 5224.

52 G. Kresse and J. Hafner, Phys. Rev. B: Condens. Matter Mater. Phys., 1993, 47, 558. 
53 J. Perdew, K. Burke and M. Ernzerhof, Phys. Rev. Lett., 1996, 77, 3865.

54 L. Wang, T. Maxisch and G. Ceder, Phys. Rev. B: Condens. Matter Mater. Phys., 2006, 73, 195107.

55 S. L. Dudarev, G. A. Botton, S. Y. Savrasov, C. J. Humphreys and A. P. Sutton, Phys. Rev. B: Condens. Matter Mater. Phys., 1998, 57, 1505.
56 J. Heyd, G. E. Scuseria and M. Ernzerhof, J. Chem. Phys., 2003, 118, 8207.

57 M. Aykol, S. Kim and C. Wolverton, J. Phys. Chem. C, 2015, 119, 19053.

58 S. Grimmea, J. Antony, S. Ehrlich and H. Krieg, J. Comput. Chem., 2011, 32, 1456.

59 G. Henkelman and H. J. Jonsson, Chem. Phys., 2000, 113, 9978. 